\title{
Desafíos del Covid-19 en materia de seguros ${ }^{1}$
}

\section{Challenges of the Covid-19 regarding insurance}

\author{
Rafael Alberto Ariza Vesga ${ }^{2}$
}

\begin{abstract}
El virus COVID-19, conocido comúnmente como Coronavirus, y las medidas adoptadas por el Gobierno colombiano para impedir su propagación, han determinado impactos en múltiples áreas de la economía nacional e internacional. La actividad aseguradora ha sido impactada igualmente, no solo desde el punto de vista del desarrollo como industria, sino también por las diferentes hipótesis de reclamación que pueden darse en los diferentes ramos de seguro y que pueden generar controversias significativas. El presente artículo pretende mostrar los desafíos más sobresalientes que encontramos a la fecha desde la perspectiva de los productos de seguro y sus condiciones. Sin embargo, debemos reconocer que aún son insospechados nuevos efectos que se producirán, acorde con la duración de la pandemia y las acciones que tomen los diferentes actores económicos.
\end{abstract}

Palabras clave: COVID-19, Seguro de salud, seguro de vida, seguros de daños, seguro de responsabilidad civil, seguro de cumplimiento, fuerza mayor, teoría de la imprevisión, contrato de arrendamiento.

\section{ABSTRACT}

The COVID-19 virus, commonly known as Coronavirus, and the measures taken by the Colombian Government to prevent its spread, have determined impacts in multiple areas of the national and international economy. The insurance activity has been equally impacted, not only from the point of view

1 Fecha de recepción: 31 de mayo de 2020. Fecha de aceptación: 26 de junio de 2020 Para citar el artículo: Ariza R. "Desafíos del covid-19 en materia de seguros". Revist@ E-Mercatoria, vol. 19, $\mathrm{n}^{\circ}$ 1, junio-diciembre, 2020. DOI: https://doi.org/10.18601/16923960.v19n1.03

2 Docente investigador del Departamento de Derecho Comercial de la Universidad Externadode Colombia email: rafael.ariza@uexternado.edu.co y rafaelariza@arizaygomez.com 
of development as an industry, but also due to the different claim hypotheses that may occur in the different insurance lines that may generate significant controversies. This article aims to show the most outstanding challenges that we find to date from the perspective of the insurance products and their conditions. However, we must recognize that there are still unsuspected new effects that will occur, according to the duration of the pandemic and the actions taken by different economic actors.

Keywords: COVID-19, health insurance, life insurance, property insurance, liability insurance, bond insurance, force majeure, act of God, rebus sic stantibus-Change of Circumstances, lease agreement.

\section{PRESENTACIÓN GENERAL}

La actual pandemia declarada por la Organización Mundial de la Salud (OMS) en relación con el denominado COVID-19, comúnmente conocido como Coronavirus, ha traído y traerá significativos impactos y desafíos para todos los sectores económicos. El sector asegurador no es, de ninguna manera, ajeno a esa realidad. En este sentido, múltiples son las perspectivas desde las cuales se puede abordar el tema, pues el COVID-19 y las medidas adoptadas por los Gobiernos para contener su expansión, generan desafíos en diferentes frentes para el sector asegurador.

Los principales retos, desde la perspectiva de los aseguradores y la continuidad de esta industria, están concentrados, en primer lugar, en el desarrollo de su negocio (dificultad para la venta directa de los seguros tanto en Sucursales como a través de intermediarios de seguros, para prestar servicio al cliente a los asegurados -inspecciones y prestación de servicios-, pérdidas financieras en inversiones de las reservas constituidas, entre otros) ${ }^{3}$. Así mismo, se presentan desafíos en términos de la generación y pago de primas de seguro (renovaciones, prórrogas, pago efectivo de las primas por los asegurados) e, igualmente, en términos de siniestros (reclamaciones incrementadas a raíz del COVID-19). Las acciones y estrategias que desarrollen los aseguradores frente a estas circunstancias serán fundamentales para el futuro de la actividad.

En la perspectiva relacionada con los ingresos de las aseguradoras por concepto de primas, las preocupaciones pasan por la desaparición de empresas aseguradas o la disminución de ingresos de las personas naturales, con la consecuente no continuidad de múltiples productos de seguro, en la

3 Al respecto, se puede consultar https://www2.deloitte.com/es/es/pages/financialservices/articles/consecuencias-covid-19-sector-seguros.html\# 
medida en que las personas no cuenten con el flujo de caja necesario para mantener esas coberturas y prioricen la atención de otros conceptos, tales como los gastos primarios del hogar, el capital de trabajo, la nómina o los aportes a seguridad social. En materia de la cobertura de riesgos laborales, para colocar un ejemplo, preocupa la disminución de cotizaciones a raíz de suspensiones de contratos laborales, licencias o terminaciones de contratos de trabajo. En tratándose de seguro de transporte, otro ramo de seguro con el que podemos ilustrar esta situación, el número de despachos ha disminuido (a nivel marítimo, terrestre y aéreo), con la consecuente reducción en ingresos por concepto de primas.

En esta materia, otra de las temáticas en boga por estos días, es la obligación de la aseguradora de restituir, a lo menos parcialmente, el valor de las primas pagadas por los asegurados, cuando quiera que el riesgo ha disminuido, como podría haber acontecido en el caso de automotores que no se han podido movilizar en los periodos de cuarentena obligatoria y, por tanto, no han estado expuestos a riesgos como los de daño accidental, responsabilidad por accidente de tránsito (caso del seguro de automóviles voluntario) o se ha eliminado o disminuido la posibilidad de generar daños a víctimas por accidente de tránsito (ejemplo del SOAT). Algunas compañías de seguro han optado por brindar beneficios voluntarios a sus asegurados a raíz de esa circunstancia, con disminuciones porcentuales del valor de la prima en los meses objeto de afectación.

Por su parte, en lo relacionado con el incremento de reclamaciones a raíz de la pandemia, el manejo que los aseguradores den a esa temática determinará, a su vez, consecuencias en la percepción de los consumidores y contratantes de seguros sobre el efecto provechoso que les generan. Ello repercutirá en mayor o menor confianza de los consumidores para la adquisición de seguros tras la pandemia, de lo cual deben ser suficientemente conscientes los aseguradores.

\section{LOS DESAFÍOS EN MATERIA DE RECLAMACIONES Y SINIESTRALIDAD - PANORAMA EN ALGUNOS PRODUCTOS DE SEGURO}

Profundizando en el tema de la siniestralidad asociada a la pandemia que nos afecta, encontramos una amplia gama de productos de seguro en los que puede tener incidencia, entre los cuales se destacan los siguientes, a título enunciativo, pues las hipótesis pueden ser mucho más amplias en la práctica:

\subsection{EN SEGUROS DE PERSONAS}

2.1.1. Seguros de salud: En este tipo de seguro, los efectos tienen relación con la cobertura o no de la atención de las consecuencias de la infección por 
COVID-19. En general, salvo que exista alguna exclusión expresamente prevista en las condiciones generales o particulares del seguro, se ofrece cobertura a esas contingencias. En algunos casos, las discusiones podrían presentarse frente a la cobertura o no de algunos tratamientos experimentales frente al COVID-19, dada la ausencia de protocolos definidos y aprobados frente al citado virus. Los procedimientos experimentales o en investigación son normalmente excluidos en este tipo de seguros, así como la aplicación de vacunas, lo cual tendrá gran relevancia una vez se encuentre una de distribución masiva. En tales casos, consideramos deberá respetarse el contenido del contrato de seguro. No obstante, no podemos dejar de reconocer que se han presentado iniciativas en contextos internacionales (Estados Unidos y Reino Unido, hasta la fecha), donde se han presentado proyectos legislativos dirigidos a dejar sin efecto cláusulas de exclusión de pandemias y epidemias, por lo que el tema podría llegar a tener discusión en el futuro, máxime el activismo judicial que encontramos en contextos como el colombiano.

2.1.2. Seguros de vida: Los efectos se presentan en relación con el fallecimiento de asegurados como consecuencia de la infección por el virus COVID-19. De manera general, salvo que exista alguna exclusión prevista en las condiciones generales o particulares del seguro, se ofrece cobertura a esa contingencia (normalmente, se cubre la muerte natural por cualquier caso, salvo específicos casos excluidos).

2.1.3. Seguros de exequias: En la medida en que se produce el fallecimiento, los aseguradores cubren los gastos de sepelio del asegurado fallecido en relación con el contagio por COVID-19, aunque se ha presentado discusión sobre la evidente disminución de esos costos en favor del asegurador, pues el cadáver, en cumplimiento de los protocolos existentes, debe ser cremado con rapidez, sin servicio de velación y con acompañamiento mínimo o nulo de familiares y seres queridos. Algunos beneficiarios, seguramente, pretenderán el reconocimiento de la diferencia, cuya respuesta dependerá del carácter indemnizatorio o no de las coberturas en controversia.

2.1.4. Seguro de riesgos laborales: Si bien es una cobertura de la seguridad social en el derecho colombiano, dicho ramo de seguro ha sufrido y sufrirá una afectación con ocasión de trabajadores infectados por COVID-19 por o con ocasión de su trabajo, que requieran atención de la enfermedad o fallezcan por esa causa, en la hipótesis en que la misma sea calificada como laboral. Desde luego, existirá la discusión sobre si, efectivamente, el COVID-19 podría ser considerado como una enfermedad laboral en la medida que, se requiere demostrar la relación de causalidad entre los riesgos a los que está expuesto el trabajador y la adquisición de la enfermedad. En tal sentido, ello podría llegar 
a probarse en casos de contagio de trabajadores del sector salud encargados de la atención de enfermos en cumplimiento de su labor, a pesar de que se trate de una enfermedad que puede afectar a la generalidad de los individuos. Las discusiones, en consecuencia, requerirán una exigente labor probatoria.

\subsection{EN SEGUROS DE DAÑOS}

En esta tipología de seguros, los ramos que consideramos cuentan o contarán con afectación destacable, sin perjuicio de la existencia de otros susceptibles de consecuencias, son los siguientes:

2.2.1. Seguro de responsabilidad civil: En este ramo de seguro, como se sabe, se brinda cobertura frente a los perjuicios que causa el asegurado a terceros y que le sean imputables bajo las condiciones y límites pactados. En ese sentido, algunos seguros que ya cuentan con afectación o la tendrán son:

\subsubsection{Seguro de responsabilidad con amparo de responsabilidad patronal:}

En relación con este amparo, que se encuentra acordado en algunas pólizas de seguro de responsabilidad tomadas por empleadores o por contratistas (derivado de cumplimiento), es muy posible que se lleguen a presentar reclamaciones, frente a hipótesis en las que los empleadores no hayan proveído elementos de protección personal (EPP) suficientes a los trabajadores y se pudiera acreditar que estos adquirieron el virus, como consecuencia de un actuar descuidado o negligente en esa materia de su empleador. Sin embargo, es habitual encontrar en las condiciones de los productos de seguro que ofrecen las aseguradoras de este ramo, la exclusión de enfermedades profesionales, endémicas o epidémicas (nótese que el COVID-19 fue primero considerado como epidemia y pasó a ser pandemia por su alcance mundial). Sin perjuicio de ello, pueden existir casos en los que el trabajador pueda infectarse por el virus en una situación accidental (pinchazos, entre otras hipótesis), donde la cobertura podría llegar a operar.

2.2.1.2. Seguro de responsabilidad médica: En este producto de seguro, se espera la existencia de reclamos cuando quiera que el paciente pretenda se declare la responsabilidad de una IPS o del personal médico, por haber adquirido el virus en sus instalaciones o en desarrollo de algún procedimiento médico. En algunos de estos contratos de seguro se pueden encontrar exclusiones de cobertura frente a daños producto de contagios virales o transmisión de enfermedades (cuando el asegurado sabe o debería saber que es portador de una enfermedad, no obstante lo cual atiende - caso reciente en una localidad de Bogotá, Colombia de un profesional que continuó atendiendo, 
pese a que contaba con prueba positiva para Covid $\left.-19^{4}\right)$, al paso que existen otros productos que sólo excluyen virus específicos (no la generalidad, caso del VIH). Habrá de revisarse en cada contrato de seguro en particular, si el hecho puede encajar o no en la cobertura contratada por el profesional o la Institución de salud.

\subsubsection{Seguro de responsabilidad civil directores y administradores de} empresas o copropiedades: En este tipo de seguros, podrían llegar a presentarse reclamaciones frente al sector asegurador, producto de situaciones en las cuales los socios o acreedores de la sociedad pudieran considerar que la actuación del director o administrador de la sociedad, no se ajustó a sus deberes de buena fe, lealtad y diligencia propios de un buen hombre de negocios y que ello les causó perjuicios. Lo propio, llevado al campo de las copropiedades. Hipótesis de esta estirpe pueden darse, cuando quiera que los socios consideren que el director o administrador faltó a sus deberes al negociar o renegociar algún acuerdo de negocios, entre otros, pese a que, por su parte, el director o administrador considere que lo hizo atendiendo las circunstancias extraordinarias del COVID-19 y con el propósito de mantener en funcionamiento la empresa. (v.gr. acuerdos de descuento, otorgamiento de plazos, condonación de intereses, priorización de determinados gastos, entre otros). Se precisa que esta póliza, habitualmente, delimita en sus condiciones que no se cubren los daños de índole laboral o las lesiones corporales causadas a personas, por lo que su connotación para esta temática, estaría dada, fundamentalmente, en términos de decisiones desfavorables de negocio para la empresa.

\subsubsection{En el seguro de interrupción de negocio (BI) o todo riesgo para empre-} sas con cobertura de lucro cesante: Este tipo de seguros cubren al asegurado, entre otros aspectos, frente a la pérdida de beneficios futuros de la empresa, como consecuencia de la reducción en el volumen del negocio debido a la paralización total o parcial del mismo, ocasionada por un DAÑO FísICOMATERIAL. Aquí la discusión ha sido y será la relacionada con determinar si la afectación producida a las empresas producto del COVID-19 encaja o no en el concepto de DAÑO FísICO-MATERIAL de algún elemento de la empresa. La respuesta general ha sido negativa, razón por la cual, salvo que se haya establecido una cobertura específica frente a la interrupción derivada de PANDEMIAS O EPIDEMIAS, los aseguradores no brindan cobertura. Un caso emblemático a nivel internacional en el que sí se acordó la cobertura de la interrupción de negocio por causa de pandemias o epidemias, es el del abierto

4 Al respecto: https://www.eltiempo.com/bogota/coronavirus-en-bogota-investigan-porque-medico-fue-a-trabajar-con-la-covid-19-en-bosa- 490802 
de tenis de WIMBLEDON, en el que sí se contaba con esta cobertura, razón por la cual los aseguradores reconocerán aproximadamente 114 millones de libras esterlinas como indemnización ${ }^{5}$ (más de 541.000 millones de pesos a la fecha). Este seguro lo había tomado esta organización desde el año 2003, tras la epidemia del SARS y ahora obtiene los frutos de su previsión (pagaba aprox. 1,5 millones de libras anual por la cobertura).

2.2.3. En el seguro de cancelación de eventos: Bajo este tipo de producto se brinda protección patrimonial al asegurado frente a la CANCELACIÓN, INTERRUPCIÓN o APLAZAMIENTO de un evento que ocurran de manera repentina y accidental por una circunstancia que esté fuera del control del asegurado (climatológica, no presentación del artista, cantante, etc.), siempre y cuando dicha CANCELACIÓN, INTERRUPCIÓn o APLAZAMIENTO ocurra dentro del término de vigencia del seguro y por causa no excluida. Habitualmente se encuentran excluidas las circunstancias asociadas a EPIDEMIAS, pero pueden haberse presentado o llegar a presentarse casos en los que no resulte clara tal ausencia de cobertura. Sin perjuicio de ello, sin duda alguna, múltiples eventos a nivel mundial, adoptarán mayor conciencia sobre la protección ante este riesgo lo que, a su vez, generará un reto para el sector asegurador que decida asumirlo responsablemente desde la perspectiva técnica y jurídica.

2.2.4. En el seguro o anexo de cancelación o interrupción de viaje: En este tipo de seguro se establece, de manera general, que el asegurador reembolsará al asegurado por la pérdida irrecuperable de depósitos o gastos pagados por anticipado al transportador (marítimo, aéreo o terrestre) y porciones terrestres, si el viaje se cancela durante los días anteriores al inicio del mismo o durante el mismo, en forma necesaria e inevitable como consecuencia de, entre otros, muerte o enfermedad grave con carácter urgente que requiera internación o impida la deambulación, internación hospitalaria por accidente o enfermedad repentina y aguda del asegurado o sus familiares cercanos, cuarentena, orden de comparecencia ante la justicia posterior a la celebración del contrato de transporte $y$, finalmente, desastres naturales, que imposibiliten la iniciación o continuidad del viaje.

Esta cobertura fue y ha sido objeto de múltiples reclamaciones a raíz de las pérdidas de vuelos sufridas por múltiples asegurados, a raíz de la situación de cuarentena obligatoria declarada por el Gobierno Nacional. Al cubrirse las cuarentenas sin precisar su origen o causa, de manera general consideramos que incluye las relacionadas con Epidemias o Pandemia. Sin embargo, algunas pólizas de seguro contemplan expresamente la exclusión de PANDEMIA 
o EPIDEMIA, razón por la cual se han dado negativas a diferentes solicitudes de indemnización. En consecuencia, cada caso deberá analizarse a la luz del contrato de seguro respectivo.

2.2.5. En el seguro de transporte: Esta tipología de seguro, tampoco es ajena a la irrupción del COVID-19 y las medidas adoptadas por los gobiernos para su control. Las limitaciones al comercio nacional e internacional, con ocasión de nuevas exigencias de bioseguridad, puede alterar la operación de transporte $y$, consecuentemente, el riesgo que cubre el asegurador con circunstancias como las siguientes: Retraso (normalmente no cubierto en las pólizas de seguro del mercado); acumulación de la carga en puertos o bodegas, lo cual requiere mayores periodos de cobertura (eventualmente podría generar exigencia de prima adicional) ${ }_{i}$ cargos por demora en el cargue y descargue de mercancías que no serían recuperables en la mayoría de contratos de seguro que se ofrecen en el mercado; desviación -en el caso de puertos que no sean seguros desde el punto de vista sanitario- lo cual gozaría de cobertura generalmente, pero no los fletes y gastos de reembarque asociados; los aseguradores, así como los transportadores pueden llegar a alegar fuerza mayor lo cual puede generar alta conflictividad que solo se resolverá tras un debate probatorio detallado; y puede haber un incremento del riesgo para los aseguradores, producto de interrupciones que se puedan presentar en el transporte de la mercancía con ocasión de medidas adoptadas para evitar la extensión de la pandemia ${ }^{6}$.

\subsubsection{EN EL SEGURO DE CUMPLIMIENTO DE CONTRATOS \\ Y, EN ESPECIAL, EN EL DE ARRENDAMIENTO:}

Especial mención merece el impacto del COVID-19 en la ejecución de contratos celebrados antes de que el COVID-19 y las medidas para su mitigación irrumpieran, que estuvieran amparados bajo seguros de cumplimiento, en donde, como se sabe, el asegurador se compromete a indemnizar los perjuicios ocasionados al contratante, con ocasión del incumplimiento imputable al contratista garantizado. La gran inquietud se centra en este tipo de seguro, en determinar si el incumplimiento del contrato respectivo, es responsabilidad del contratista o si, por el contrario, las circunstancias determinadas por el COVID-19 y las medidas estatales adoptadas, son constitutivas de causales excluyentes de su responsabilidad o, eventualmente, de la irrupción de un

$6 \mathrm{Al}$ respecto, se pueden obtener consideraciones adicionales en: http://t21.com.mx/ maritimo/2020/04/08/como-mitigar-impacto-covid-19-transporte-maritimo-puertos. En el caso del transporte público en América Latina, se puede considerar el siguiente link: https://revistaconstruir.com/cuando-el-mundo-deja-de-moverse-los-efectos-delcovid-19-el-transporte-de-america-latina-y-el-caribe/ 
acontecimiento imprevisto que desequilibra las cargas contractuales (esto último, en contratos de ejecución sucesiva). En el caso del seguro de cumplimiento del contrato arrendamiento (comúnmente conocido como seguro de arrendamiento), la pregunta consistirá, específicamente, en determinar si el impago o mora en el pago de los cánones de arrendamiento por parte del arrendatario le resulta imputable o no a este, teniendo en cuenta que las medidas adoptadas por las autoridades para enfrentarlo han determinado la imposibilidad de utilizar el bien como tal (por razón del aislamiento obligatorio, como acontece con miles de locales comerciales) o se ha determinado una pérdida súbita de los ingresos con los que el arrendatario atendía sus obligaciones contractuales (disminución o reducción total de ventas en el caso de locales comerciales o reducción del salario-ingreso o pérdida del empleo, en el caso de los inmuebles destinados a vivienda).

En el caso del seguro de cumplimiento bajo sus distintas modalidades, la exigencia de la IMPUTABILIDAD del incumplimiento al contratista garantizado resulta clara al revisar los diferentes productos que se encuentran en el mercado nacional. Los amparos son definidos, generalmente, de la siguiente manera:

a) Seguro de cumplimiento particular (amparo de cumplimiento): Se ampara a la entidad contratante asegurada única y exclusivamente contra los perjuicios directos derivados del incumplimiento imputable al contratista garantizado. ${ }^{7}$

Es habitual encontrar como causal de exclusión, en armonía con lo anterior, la de CAUSA EXTRAÑa o, la "FuERZA MAYOR O CASO Fortuito O Cualquier Otra Causal legal De Exoneración De Responsabilidad Del Contratista Garantizado".

b) Seguro de cumplimiento estatal (garantía única de cumplimiento): Dada su relevancia desde la perspectiva pública, es el Artículo 2.2.1.2.3.1.7. del Decreto 1082 de 2015 el que define el riesgo cubierto en el amparo de cumplimiento y ratifica la necesidad de IMPUTABILIDAD del incumplimiento. Señala esta disposición en su numeral 3:

"Garantía de cumplimiento. La garantía de cumplimiento del contrato debe cubrir:

(..)

3. Cumplimiento del contrato. Este amparo cubre a la Entidad Estatal de los perjuicios derivados de:

7 En este sentido, se pueden consultar, entre otros, https://www.libertycolombia.com $\mathrm{co} / \mathrm{sites} / \mathrm{default} / \mathrm{files} / 2019$-09/P\%C3\%B3liza\%20Cumplimiento\%20para\%20Particulares\%20Septiembre\%202019.pdf, https://segurosstorage.blob.core.windows.net/ documentos/CUMPLIMIENTO _ ENTRE _ PARTICULARES.pdf ó https://www.segurossura. com.co/documentos/condicionados/empresas/cumplimiento/particulares.pdf 
3.1.El incumplimiento total o parcial del contrato, cuando el incumplimiento es imputable al contratista

3.2.El cumplimiento tardío o defectuoso del contrato, cuando el incumplimiento es imputable al contratista

3.3.Los daños imputables al contratista por entregas parciales de la obra, cuando el contrato no prevé entregas parciales; y (Negrilla fuera de texto).

Armónicamente, el artículo 2.2.1.2.3.2.3. del mismo Decreto, admite que los aseguradores puedan contemplar en este tipo de póliza como exclusión, la de CAUSA EXTRAÑA. En efecto, establece la norma:

"Exclusiones. La Entidad Estatal solamente admitirá las siguientes exclusiones, en el contrato de seguro que ampara el cumplimiento de los contratos que suscriba, y cualquier otra estipulación que introduzca expresa o tácitamente exclusiones distintas a estas, no producirá efecto alguno:

1. Causa extraña, esto es la fuerza mayor o caso fortuito, el hecho de un tercero o la culpa exclusiva de la víctima. (...)"

c) En los seguros de arrendamiento, la situación no es distinta. al revisar diferentes condiciones contractuales que se encuentran en el mercado, se encuentra que el objeto de este seguro es pagar las obligaciones correspondientes a canon de arrendamiento y reajustes, cuotas de administración ordinarias y valor de servicios públicos, en caso de que el arrendatario no las cumpla según el contrato de arrendamiento que tiene con el asegurado. Es habitual encontrar la exclusión de "La fuerza mayor y/o caso fortuito y/o causa extraña y/o cualquier otra causal legal de exoneración de responsabilidad del arrendatario, independientemente de los hechos o circunstancias que contractualmente se califiquen como fuerza mayor y/o caso fortuito y/o causa extraña. La fuerza mayor y/o caso fortuito y/o causa extraña no amparados por esta póliza, serán aquellos que cumplan con los requisitos establecidos en el régimen legal colombiano." y actos de autoridad. ${ }^{8}$

Así las cosas, el debate en estas modalidades de seguro girará, principalmente, en determinar si se presenta o no una situación de IMPUTABILIDAD del incumplimiento en cabeza del contratista garantizado, (para el caso de arrendamiento, del arrendatario) constitutiva de SINIESTRO, respecto de contratos

$8 \mathrm{Al}$ respecto, se puede consultar, entre otros, https://www.segurossura.com.co/documentos/condicionados/personas/vivienda/arrendamiento.pdf, https://www. arriendosmundial.com/media/Seguro_individual_arrendamiento_inmuebles_vivienda.pdf, https://s3-us-west-2.amazonaws.com/sitesegurosbolivar/wp-content/ uploads/2019/10/28213228/Clausulado-Arrendamiento.pdf 
celebrados ANTES de que todo este escenario irrumpiera. Sobre ese punto las respuestas han sido disímiles y dependen mucho de lo que figure pactado en el contrato específico, así como de la aplicación de la teoría general de las obligaciones y la responsabilidad contractual en el caso concreto.

Equiparar una pandemia como la del COVID-19 con un evento de fuerza mayor o caso fortuito excluyente de responsabilidad por sí misma, no consideramos resulte posible hacerlo de manera indiscriminada, pues la misma afecta y ha afectado a los individuos y empresas de manera disímil. En consecuencia, el análisis sobre la IRRESISTIBILIDAD varía. Así, por ejemplo, en el caso de actividades eximidas de las medidas de aislamiento obligatorio, la gran mayoría de contratos han tenido la continuidad habitual, salvo contados aspectos, en términos del cumplimiento de medidas de protección adicionales para su realización. En el mismo sentido, los contratos cuyo objeto puede ser atendido a través de medios electrónicos (consultoría, asesoría, servicios inmateriales), no están en términos generales frente a una situación que, bajo características de irresistibilidad, impidan su ejecución. Es por ello que coincidimos con diferentes opiniones que se han emitido en ese sentido, que concluyen que la pandemia, por sí sola, NO constituye un hecho justificativo o una causa extraña, pues sus efectos varían en cada contrato particular. En cada caso concreto habrá de determinarse si la PANDEMIA o si las medidas adoptadas por el Gobierno Nacional, departamental o municipal para contenerla, han determinado de manera EFICIENTE la imposibilidad absoluta, definitiva y justificada para cumplir con determinada obligación o cumplirla de manera defectuosa reuniendo los requisitos de este fenómeno jurídico (imprevisibilidad, irresistibilidad y externa o ajena al deudor de la obligación). ${ }^{9}$ Bajo este planteamiento, incluso, lo que debe valorarse, más que la pandemia en sí misma, son las órdenes y determinaciones que los Gobiernos han dictado en el marco de la emergencia sanitaria, lo cual ha tenido efectos en la economía que podrían evaluarse a partir de la teoría del "hecho del príncipe" existente en materia administrativa.

Para otros, en un análisis general, la pandemia sí constituiría una circunstancia de caso fortuito o fuerza mayor (sin distinguir entre el virus mismo y las medidas que los Gobiernos han adoptado para contenerla) ${ }^{10}$. Sin embargo,

9 En este sentido, por ejemplo, ARAMBURO, Maximiliano en: https://www.ambitojuridico. $\mathrm{com} /$ noticias/columnista-impreso/administrativo-y-contratacion/pandemia-y-fuerzamayor Artículo de 27 de marzo de 2020 publicado en el periódico "Ámbito Jurídico" o artículo de la firma Chevez Ruiz, Zamarripa en el contexto mexicano que se puede consultar en: https://www.chevez.com/upload/files/Topico_2020-1.pdf. Igualmente, para el caso de la posibilidad de alegar fuerza mayor o caso fortuito en contratos de arrendamiento, reciente artículo de opinión en https://www.asuntoslegales.com.co/ consumidor/la-causa-de-fuerza-mayor-una-figura-aplicable-a-arrendamientos-entiempos-del-covid-2999682 http://www.saij.gob.ar/pablo-carlos-barbieri-pandemia-como-caso-fortui- 
estimamos que dicha posición no resulta apropiada pues, como ya lo hemos señalado, debe necesariamente partirse de un análisis sobre el contenido de los Decretos emitidos por el Gobierno en el marco del Estado de Emergencia, así como los municipales o distritales que hayan establecido o establezcan restricciones adicionales, para determinar si, efectivamente o no, el contratista fue afectado por esta situación, si está frente a una circunstancia irresistible en realidad. No podemos dejar de recordar, como lo señalaba el maestro HINESTROSA, que: "La imposibilidad ha de diferenciarse de la dificultad, como también de la onerosidad. La verdadera imposibilidad es la absoluta, esto es, la que es tal, "considerada en sí y de por sí", o sea una imposibilidad originada en un elemento extraño a la persona del deudor o a su economía. El obstáculo ha de ser absoluto, insuperable, impossibilitas, y no consistir en una simple dificultad, difficultas praestandi, personal, económica o material, circunscrito a la persona del deudor o a sus circunstancias individuales, fenómeno este que se identifica con la expresión difficultas."11 (Negrilla fuera de texto).

Un aspecto adicional que debe ser estudiado, si se considera que las circunstancias asociadas al COVID-19 pueden configurar fuerza mayor o caso fortuito, es el contenido del contrato respectivo en cuanto a si se pactó algo o no entre las partes, en materia de asunción de tal tipo de riesgo. En efecto, es posible que los contratantes hayan distribuido de manera anticipada los riesgos en el contrato, como lo permiten los artículos 1604 (pacta sunt servanda), 1616 y concordantes del Código Civil, aplicables analógicamente en materia mercantil. Si existe pacto expreso al respecto, en virtud del cual, una de las partes asumió el riesgo de fuerza mayor o caso fortuito, ya no le será posible alegarlos como causal eximente de su responsabilidad. Por el contrario, si no hubo pacto expreso, la regla general es que "la mora producida por fuerza mayor o caso fortuito, no da lugar a indemnización de perjuicios", conforme lo prevé el artículo 1616 del Código Civil.

Si luego de este análisis, se concluye que el incumplimiento de las obligaciones obedece a una situación de fuerza mayor o caso fortuito para el contratista, se configurará la causal de exclusión prevista en la generalidad de seguros de cumplimiento y de arrendamiento, por lo que el asegurador NO pagará indemnización.

to - fuerza-mayor-dacf $200035-2020-03-25 / 123456789-0$ abc-de fg5300-02fcanirtcod? \&o =4\&f=Total\%7CFecha\%7CEstado\%20de\%20Vigencia\%5B5 \%2C1\%5D\%7CTema\%5в5\%2C1\%5D\%7COrganismo\%5в5\%2C1\%5D\%7CAutor\%5B5\% 2C1\%5D\%7CJurisdicci\%F3n\%5B5\%2C1\%5D\%7CTribunal\%5B5\%2C1\%5D\%7CPublicac i\%F3n\%5B5\%2C1\%5D\%7CColecci\%F3n\%20tem\%E1tica\%5B5\%2C1\%5D\%7CTipo\%20 de\%20Documento/Doctrina\& $\mathrm{t}=5$

11 Hinestrosa, Fernando, Tratado de las Obligaciones: Concepto, estructura, vicisitudes, Bogotá D.C., Universidad Externado de Colombia, 2003, pág. 778. 
Otro abordaje que puede tener el impacto de la pandemia en los contratos de ejecución o tracto sucesivo que se encuentren asegurados - dentro de los cuales está el de arrendamiento, no aplicable a contratos aleatorios o de ejecución instantánea-es el de considerar la situación presentada, a la luz de la teoría de la imprevisión. Bajo dicha teoría, que corresponde al desarrollo de la cláusula rebus sic stantibus ("estando así las cosas"), se tendría a la pandemia del COVID-19 como un acontecimiento o circunstancia extraordinaria que se presenta de manera sobrevenida e imprevista para los contratantes, que causa una ruptura grave en el equilibrio de las prestaciones del contrato. Debe tratarse de una circunstancia que no esté dentro del alea normal del contrato y respecto de la cual NO se hubiere acordado nada entre las partes bajo el esquema de distribución de los riesgos a la que ya hemos hecho referencia.

Ello permitiría a la parte que sufre los efectos de esa situación imprevista, pedir la revisión judicial del equilibrio del contrato o, de no ser posible definitivamente, su terminación, aplicando principios como los de buena fe contractual, equidad y justicia contractual. El objetivo fundamental bajo la aplicación de esta teoría, es preservar la continuidad del negocio jurídico, salvo que se haga de imposible cumplimiento, restableciendo el equilibrio al interior del mismo, evitando un lucro excesivo de uno de los contratantes en perjuicio del otro. ${ }^{12}$

Para la aplicación de esta teoría, tal como lo ha desarrollado la jurisprudencia nacional:

... la parte que considere que puede prevalerse de la acción tipificada [...] habrá de probar lo siguiente: 4.1. Un contrato de ejecución sucesiva, periódica o diferida, del cual se deriven aún prestaciones de futuro cumplimiento. Así mismo, la ocurrencia de circunstancias extraordinarias, imprevistas o imprevisibles, posteriores al perfeccionamiento del referido negocio jurídico, que alteren el valor u onerosidad de esa futura o futuras prestaciones, en un grado tal, que resultan excesivamente gravosas o ruinosas para el obligado demandante" ${ }^{113}$ (Negrilla fuera de texto).

La Corte Suprema de Justicia, Sala de casación civil en sentencia del 21 de febrero de 2012, M.P.: William Namén Vargas ${ }^{14}$ precisó el entendimiento del

12 Sobre este tema, se puede consultar también: http://www.isanin.com.co/es/covid19-fuerza-mayor-y-teoria-de-la-imprevision/

13 Sentencia de 16 de mayo de 2005, del Tribunal Superior Judicial de Bogotá, Sala Civil citada en: FrANCO ZÁrATE, JAVIER, "La excesiva onerosidad sobrevenida en la contratación mercantil: una aproximación desde la perspectiva de la jurisdicción civil en Colombia", Revista de derecho privado, Universidad Externado de Colombia, 2012, consultable: https://revistas.uexternado.edu.co/index.php/derpri/article/view/3309/3458 
concepto "excesiva onerosidad" que exige la teoría de la imprevisión, en los siguientes términos:

"Es indispensable un desequilibrio prestacional cierto, grave, esencial, fundamental, mayúsculo, enorme o significativo, y no cualquiera, a punto de generar excesiva onerosidad transitoria o permanente de la prestación futura, una desproporción grande con su incremento desmesurado o sensible disminución de la contraprestación, ya una pérdida patrimonial, por reducción del activo, ora de la utilidad esperada, bien por aumento del pasivo, suscitada por los acontecimientos sobrevenidos, imprevistos e imprevisibles, con los cuales debe tener una relación indisociable de causa a efecto" (Negrilla fuera de texto).

Llevado lo anterior a lo que viene aconteciendo a raíz del COVID-19 y las medidas para mitigarlo, estimamos que si se trata de contratos directamente afectados por esas determinaciones en virtud de las cuales no se pueden ejercer o están altamente limitadas y afectadas -caso de los restaurantes, las aerolíneas, los comercios al detal o en las cuales se precisa de la aglomeración de personas- bien podría considerarse que se presenta una situación extraordinaria e imprevisible respecto de la cual se puede solicitar el restablecimiento judicial del equilibrio del contrato respecto de prestaciones futuras ${ }^{15}$. Sin embargo, la aplicación del equilibrio económico roto requiere que sea determinada por un Juez ó arbitro (lo cual toma un tiempo considerable), sumado a que el operador judicial solo podría pronunciarse respecto a las "prestaciones de futuro cumplimiento" como lo prevé el artículo 868 del C.Co. y, por tanto, las medidas que buscan restablecer el equilibrio únicamente podrían desplegar sus efectos frente a prestaciones no ejecutadas. Ello nos lleva a pensar, que la teoría de la imprevisión no será el instrumento más idóneo desde la perspectiva contractual para dar solución al impacto del Covid-19 en múltiples contratos. Las medidas asociadas al COVID-19 han determinado en casos específicos, donde se debe probar lo correspondiente, la imposibilidad de cumplir el objeto contractual lo cual es distinto en nuestra consideración. Ejemplo de ello, en los contratos de arrendamiento

15 En respaldo de esta posición, la Corte Constitucional, en sentencia C-252 de 1998 afirmó tratándose de contratos de mutuo:

"Es claro que el cambio de la situación económica existente al momento de contratar el mutuo, puede bacer que éste se torne más favorable para una de las partes. Así, un alza general, en las tasas de interés, aparentemente, perjudica al acreedor obligado a respetar el término, porque de no ser así podría colocar su dinero a un interés mayor, y una baja en las tasas de interés, en principio, perjudica al deudor que no puede pagar anticipadamente, consiguiendo otro crédito a un interés menor. Dentro de ciertos límites, estos cambios bacen parte de las contingencias propias de la vida de los negocios. Si el cambio fuere tan grande, y ocasionado, además, por circunstancias extraordinarias, imprevistas o imprevisibles, que la obligación a cargo de una de las partes resulte excesivamente onerosa, es claro que ésta podrá invocar la teoría de la imprevisión, a la cual se refiere concretamente el artículo $868 \mathrm{del}$ Código de Comercio". (Negrilla fuera de texto). 
comercial, la imposibilidad para el arrendatario de utilizar el local comercial, por la necesidad de dar cumplimiento a órdenes gubernamentales que, así mismo, tiene incidencia desde la perspectiva del cumplimiento de las obligaciones del arrendador, que tampoco puede permitirle la utilización e ingreso al arrendatario. Puede llegar a presentarse, de otra parte, el fenómeno de la insolvencia del deudor, lo cual tendrá otro tratamiento jurídico para los efectos del contrato respectivo.

En efecto, no dejan de surgir inquietudes sobre la aplicación de la teoría de la imprevisión en estas circunstancias, que sólo podrán resolverse al solucionar el caso específico: ¿Acaso quien se compromete a pagar periódicamente una determinada suma de dinero, no tiene dentro de los riesgos a que está expuesto y que conoce al momento de celebrar el contrato, el perder o disminuir súbitamente la fuente de ingresos que le permite honrar las obligaciones de género que adquirió? Nótese que, incluso, existen en el mercado asegurador productos de protección frente al desempleo y el propio sistema de seguridad social contempla algunos subsidios a cargo de las cajas de compensación familiar para precaver los efectos del desempleo. Esta inquietud se puede llevar al escenario de los contratos de arrendamiento, cuando se presenta la pérdida del empleo o del ingreso del arrendatario que le permitía pagar el canon y las cuotas de administración por razón de esta pandemia o de las medidas que adoptó el Gobierno a causa de ella. ¿Ello justifica al arrendatario dejar de pagar, temporalmente, el canon de arrendamiento? Incluso, tratándose de una obligación de dinero, que es un género, se ha entendido jurisprudencialmente que la fuerza mayor NO exonera de responsabilidad al deudor, en la medida en que no existe una imposibilidad absoluta y permanente para el cumplimiento de la obligación. En ese sentido se pronunció la Corte Suprema de Justicia, en sentencia de 5 de junio de 1935 M.P. Eduardo Ángel Zuleta:

"De todo lo cual resulta que ningún acontecimiento, sea cual fuere la naturaleza de éste, puede constituir con respecto a una determinada obligación en dinero (...) fuerza mayor o caso fortuito liberatoria, porque - según se ha visto - la fuerza mayor liberatoria supone imposibilidad absoluta de ejecución (es decir, una imposibilidad, que por ser absoluta, se aprecia, no con respecto a las condiciones peculiares del deudor, sino con relación a un tipo abstracto de deudor), y es claro que no se concibe tal imposibilidad para la entrega de una suma de dinero, así como no se concibe, en general, para las obligaciones de género: genera no pereunt".

Como se aprecia la solución no es sencilla y puede llegar a tener respuestas distintas en el escenario judicial, por lo que someterse a tal azar, puede no ser lo más recomendable para los contratantes. Es por ello que la búsqueda de soluciones entre las mismas partes, por la vía de los otrosíes, la conciliación o la transacción adquieren gran relevancia. 
El Decreto 579 de 15 de abril de 2020 emitido por el Ministerio de Vivienda ${ }^{16}$ en el marco de la emergencia económica, social y ecológica decretada a raíz de los efectos del COVID-19, apunta en esa dirección para el caso específico de los contratos de arrendamiento celebrados por personas naturales, micro empresas, PYMES y personas sin ánimo de lucro (no aplica a leasing habitacional y leasing comercial). Se reconoce que, lo ideal, es que las propias partes busquen una solución directa a su situación, teniendo en cuenta el conocimiento que tienen uno del otro y de la configuración del negocio jurídico respectivo.

En efecto, el decreto contempla:

a) La suspensión de desalojos por incumplimiento en los pagos, sin importar su periodo, hasta el 30 de junio de 2020 con el fin de proteger a los arrendatarios que requieren un lugar donde pasar el aislamiento obligatorio.

b) Aplazar el reajuste de cánones, aún los ya pactados, hasta el 30 de junio de 2020, pero debiendo el arrendatario pagar esos valores en el período que le haga falta para culminar el periodo contractual. Se trata, en consecuencia, simplemente de una suspensión temporal en la exigibilidad de esos reajustes.

c) Se conmina a las partes (se utiliza el verbo "deberán") a llegar a un acuerdo directo sobre las condiciones especiales en que se pagarán los cánones desde la vigencia del derecho hasta el 30 de junio de 2020, SIN intereses de mora, penalidades, indemnizaciones o sanciones. Esta disposición, en consecuencia, equipararía la situación a un evento de FUERZA MAYOR O CASO FORTUITO, en el que incluso inaplica cualquier estipulación especial que hubiera en el contrato de arrendamiento. Establece reglas supletivas en caso de no llegarse a un acuerdo, eliminando la posibilidad, de todas maneras, del cobro de intereses de MORA, penalidades o sanciones. Habilita únicamente al cobro de intereses corrientes en el equivalente al 50\% del interés bancario corriente por los cánones en mora entre la vigencia del decreto y el 30 de junio de 2020.

d) Establece de manera supletiva, la prórroga de los contratos que tuvieren terminación en el periodo de emergencia económica y hasta el 30 de junio de 2020. Sin embargo, las partes pueden acordar en contrario.

e) Se suspende la entrega de inmuebles con fecha para el efecto en vigencia de la emergencia, hasta el 30 de junio de 2020. 
Estas reflexiones en punto del contrato de seguro de arrendamiento, vale la pena anotarlo, también pueden resultar aplicables en el campo de la fianza inmobiliaria ${ }^{17}$ (mecanismo utilizado en la práctica por algunos arrendadores para protegerse frente al incumplimiento del arrendatario), donde la pregunta sobre la imputabilidad del incumplimiento y la solvencia del arrendatario, determinan o no el surgimiento de obligaciones para el fiador.

Si el asegurador paga los perjuicios del incumplimiento (en el caso del arrendamiento, los cánones de arrendamiento y cuotas de administración impagas) al encontrar acreditado el siniestro, al momento de ejercer la SUBROGACIÓN frente al contratista garantizado también se podrán presentar dificultades, en la medida en que el contratista garantizado (arrendatario en arrendamiento), considere que la aseguradora pagó injustificadamente. Ello determina, en consecuencia, la necesidad de que los aseguradores sean muy cuidadosos al momento de indemnizar en esta tipología de seguros.

2.2.7. En seguros de crédito: A través de este tipo de seguro, se ampara al asegurado en las pérdidas netas y definitivas que sufra por el no pago de los costos asegurados o de los créditos que haya concedido, como consecuencia directa de la insolvencia o de la mora prolongada de su deudor. Se ampara al acreedor frente al impago de cuentas por cobrar que tiene a su favor un deudor. Este seguro ha sufrido importante impacto, en la medida en que múltiples deudores han suspendido pagos a raíz de la situación económica generada por las medidas establecidas para atender la pandemia. Sectores económicos como el de la electrónica y la tecnología, productos petroquímicos (pese al incremento de la demanda de propileno para mascarillas), automovilístico y textil han tenido afectaciones en su cadena de suministro y menores ventas. Ello afectará su liquidez y, consecuentemente, eleva los riesgos de crédito amparados en este tipo de pólizas.

En este tipo de seguros, de manera general se ha sostenido que "como la causa inmediata de la pérdida es incumplimiento o falta de pago, la cobertura no considera la causa subyacente de la pérdida, si no se excluye ${ }^{\prime \prime 18}$. Solamente en la medida en que estuvieren excluidas las situaciones derivadas de pandemia o epidemias u órdenes de autoridades estatales, podría eventualmente producirse una negativa a la indemnización.

17 Ejemplos de fianza inmobiliaria en Colombia, se pueden consultar desde la práctica, en sitios web como: https://www.afiansa.com/, https://fianzainmobiliariadebogota.com/.

18 Fuente: https://www.marsh.com/mx/insights/research/repercusiones-covid-segurosriesgo-credito-y-garantias.html 


\section{CONCLUSIONES}

Tal como se desprende del análisis efectuado en estas líneas, las incidencias y desafíos para el sector asegurador a raíz de la pandemia son múltiples y determinan consecuencias en una gran gama de productos de seguro, tanto de personas, como de daños. No existen referentes o experiencias que permitan señalar con precisión cuál será el destino final de todos estos temas, mucho menos si se tiene en cuenta que aún no es fácil determinar cuál será la duración definitiva de esta pandemia ante la posibilidad de que el virus se haga endémico y se produzcan nuevas oleadas. Así mismo, se desconocen cuáles serán los efectos a largo plazo que tendrá en la economía. Como si lo anterior fuese poco, es posible, igualmente, que se presenten discusiones entre los aseguradores y sus reaseguradores, por la eventual cobertura o no del riesgo de pandemia en los diferentes productos de seguro, la cual puede tener diferencias entre las condiciones pactadas en los contratos de seguro celebrados y lo establecido en las condiciones del contrato de reaseguro respectivo.

Por esa razón, este tema continuará en discusión por un tiempo considerable, en el que sólo la voluntad decidida de los aseguradores o las decisiones judiciales definitivas, permitirán obtener mayor certeza sobre los criterios que en materia de indemnización o reconocimiento de la suma asegurada se seguirán. Sin perjuicio de ello, sí consideramos que el sector asegurador debe ser consciente del especial momento histórico en el que se encuentra, durante el cual resulta clave seguir un rumbo que permita generar mayor confianza en la comunidad en cuanto a los beneficios de contratar este tipo de protecciones. Ello puede exigir algunos sacrificios, pero seguramente redundarán en la consolidación del seguro, como herramienta por excelencia para hacer frente a los efectos nocivos de la realización del riesgo.

\section{BIBLIOGRAFÍA}

Hinestrosa, Fernando, Tratado de las Obligaciones: Concepto, estructura, vicisitudes, Bogotá D.C., Universidad Externado de Colombia, 2003.

Ossa, J. Efrén, Teoría General del Seguro: El Contrato. Bogotá D.C., Editorial Temis, 1991.

FRANCO ZÁRATE, JAVIER, "La excesiva onerosidad sobrevenida en la contratación mercantil: una aproximación desde la perspectiva de la jurisdicción civil en Colombia", en Revista de derecho privado, Universidad Externado de Colombia, 2012 


\section{Jurisprudencia}

Corte Suprema de Justicia, sentencia de 5 de junio de 1935, M.P. Eduardo Ángel Zuleta

Corte Suprema de Justicia, Sala de casación civil, sentencia del 21 de febrero de 2012, Radicación 11001-3103-040-2006-00537-01, M.P.: William Namén Vargas

Consejo de Estado, Sala de lo Contencioso Administrativo, Sección Tercera, Rad. 2742 sentencia de 20 de septiembre de 1979 C.P. Jorge Valencia Arango.

\section{Artículos web}

Posibles consecuencias del COVID-19 para el sector de los seguros, fuente: https:// www2.deloitte.com/es/es/pages/financial-services/articles/consecuencias-covid19-sector-seguros.html\#

COVID-19: Repercusiones en los seguros de riesgo de crédito y garantías, fuente: https://www.marsh.com/mx/insights/research/repercusiones-covid-segurosriesgo-credito-y-garantias.html

¿Cómo mitigar el impacto del Covid-19 en el transporte marítimo y puertos? Fuente: http://t21.com.mx/maritimo/2020/04/08/como-mitigar-impacto-covid19-transporte-maritimo-puertos 